\title{
PENERAPAN REVERSE ENGINEERING DALAM PENENTUAN POLA INTERAKSI SEQUENCE DIAGRAM PADA SAMPEL APLIKASI ANDROID
}

\author{
Vierdy Sulfianto Rahmadani' ${ }^{1)}$, Indra Kharisma Raharjana ${ }^{2)}$, Taufik ${ }^{3)}$ \\ Program Studi Sistem Informasi, Fakultas Sains dan Teknologi, Universitas Airlangga \\ Kampus C Mulyorejo, Surabaya \\ 1)vierdy-sr-10@fst.unair.ac.id \\ 2)indra.kharisma@fst.unair.ac.id \\ ${ }^{3)}$ taufik@fst.unair.ac.id
}

\begin{abstract}
Abstrak-Tujuan penelitian ini adalah penerapan reverse engineering untuk penentuan pola interaksi Sequence diagram yang bisa digunakan oleh sistem analis sebagai pola templateuntuk mendesain UML sequence diagram. Aplikasi yang digunakan sebagai data dasar berasal dari aplikasi contoh milik Android, aplikasi inilah yang mengalami proses reverse engineering dan teridentifikasi polanya. Tahap pertama yang dilakukan dalam penentuan pola interaksi ini adalah pengumpulan aplikasi dataset. Tahapan selanjutnya adalah identifikasi fitur dan aktifitas aplikasi, melakukan reverse engineeringsehingga didapatkan model sequence diagram,kemudian melakukan sistesis semua model tersebut menjadi pola interaksi sequence diagram. Langkah terakhir adalah menguji pola tersebut dengan menerapkannya dalam pembangunan aplikasi studi kasus. Berdasarkan hasil evaluasi, disimpulkan bahwa pola interaksi pada sequence diagram yang didapatkan dari penelitian ini dapat diterapkan pada perancangan perangkat lunak yang memiliki fiturfitur yang sama dengan fitur-fitur yang terdapat pada penelitian ini.
\end{abstract}

Kata Kunci- Reverse Engineering, Pola Interaksi, Sequence Diagram, Android

Abstract-The purpose of this research is to apply the application of reverse engineering to determine interaction patterns of the Sequence diagram that can be used by system analysts as a template for designing UML sequence diagrams. Sample applications from android are used as dataset for reverse engineering and pattern identification. The first step is collecting application datasets. The next stage is identifying the features and applications activity, reverse engineering to obtain a sequence diagram model, and then synthesize all of the models into an interaction pattern of sequence diagram. The final step is to test the patterns by implementing it in an application development case stud. The evaluation results concludes that interaction patterns of sequence diagram designs obtained in reverse engineering steps is able to be implemented in software development that contained similar features with the obtained features in this research.

Keywords - Reverse Engineering, Interaction Pattern, Sequence Diagram, Android

\section{PENDAHULUAN}

Unified Modelling Language (UML) telah menjadi standar dalam pengembangan perangkat lunak secara baku. UML memiliki berbagai jenis diagram, yang dikategorikan menjadi dua kategori diagram, yaitu diagram yang berisi informasi struktural, dan diagram tentang informasi perilaku (Pressman, 2010). Permasalahan yang terjadi ketika menggunakan diagram UML adalah hal konsistensi antara diagram yang dibuat dan ketika implementasinya (Xiaoshan, 2006). ketidak konsistenan antara diagram desain dan implementasi akan berdampak pada terhambatnya proses pengembangan perangkat lunak maupun sulitnya perawatan perangkat lunak. Tidak konsistennya perangkat lunak bisa dibedakan menjadi dua yaitu tidak lengkapnya dokumen desain dan dokumen desain yang tidak singkron dengan source code selama proses pembangunan perangkat lunak (Mens, Van Der Straeten, \& Simmonds, 2003).
Untuk mengatasi permasalahan konsistensi antara diagram dan implementasinya, diusulkan untuk melakukan proses reverse engineering dari working code yang telah ada menjadi model diagram UML, dengan demikian model diagram yang dihasilkan merupakan representasi dari aplikasi yang telah jadi dan diharapkan memiliki konsistensi yang baik. Reverse engineering adalah sebuah cara mengubah source code menjadi model desain yang digunakan dalam rekayasa ulang sistem (Stringfellow, 2006). Tujuan utama dalam reverse engineering adalah untuk menghasilkan pandangan alternatif pada sistem, memulihkan kehilangan informasi, mendeteksi kesalahan sistem, mensintesis abstraksi sistem yang lebih tinggi, dan memfasilitasi reengineering (Tonella \& Potrich, 2005).

Sebuah pola desain mempunyai tujuan tersendiri, yang juga mendeskripsikan role, responsibility, dan kolaborasi dari masingmasing kelas atau instance yang terlibat. Pola 
dalam desain digunakan sebagai garis besar pengembangan aplikasi. Dengan ekstraksi pola desain dari source code, desain dan contoh dari sistem perangkat lunak didapatkan.(Shi \& Ollson, 2006).

Dengan konsistensi dalam sebuah desain perancangan perangkat lunak, pengembangan perangkat lunak kedepannya dapat mengacu pada desain perangkat lunak. Pendekatan Model-Driven Architecture bisa dilakukan setelah penelitian ini. Pada penelitian ini, diterapkan proses reverse engineering pada sampel aplikasi Android. Tujuan penelitian ini untuk menemukan pola interaksi sequence diagram, agar konsistensi antara desain dan implementasi perangkat lunak dapat dicapai, melalui penerapan pola interaksi sequence diagram pada perancangan perangkat lunak.

\section{TINJAUAN PUSTAKA}

Software reengineering adalah pemeriksaan dan perubahan terhadap sebuah subyek sistem untuk menyusun kembali ke dalam sebuah bentuk yang baru dan implementasi yang sesuai dari bentuk yang baru tersebut. Software reengineering adalah proses rekayasa ulang yang mencakup 4 (empat) tujuan, yaitu Understanding (predictive), Repairing (corrective), Improving (perfective), dan Evolving (adaptive). Reengineering terdiri atas dua proses utama yaitu reverse engineering dan forward engineering.

Reverse Engineering merupakan proses yang tidak melibatkan perubahan pada sistem. sebuah sistem software dianalisis untuk mengekstrak informasi dari software, maka pilihan yang harus dilakukan adalah antara analisis static dan dynamic (Tonella \& Potrich, 2005).

Sequence diagram menggambarkan interaksi antar objek di dalam dan di sekitar sistem berupa message yang digambarkan terhadap waktu. Sequence diagram terdiri atar dimensi vertikal (waktu) dan dimensi horizontal (objek-objek yang terkait). Sequence diagram biasa digunakan untuk menggambarkan skenario atau rangkaian langkah-langkah yang dilakukan sebagai respons dari sebuah event untuk menghasilkan output tertentu.

Dalam penelitian ini alat yang digunakan adalah ModelGoon UML4Java. ModelGoon UML4Java adalah sebuah tools atau plugin yang disematkan dalam IDE Eclipse untuk menggambarkan class diagram dan sequence diagram.

\section{Metode PENELITIAN}

Langkah-langkah penerapan reverse engineering untuk menentukan pola interaksi
Sequence diagram dalam perancangan sampel perangkat lunak sistem operasi Android adalah:

\section{A. Pengumpulan Data Aplikasi}

Proses ini mengumpulkan aplikasi berbasis android yang nantinya digunakan sebagai dasar penyusunan interaksi pola sequence diagram. Identifikasi dilakukan dengan uji run untuk mengetahui bahwa sampel tersebut adalah sampel yang termasuk working code (berhasil berjalan tanpa error pada emulator atau device).

\section{B. Identifikasi Fitur}

Setiap aplikasi mempunyai fungsi spesifik, yang disebut fitur. Fitur setiap aplikasi diidentifikasikan untuk dibuat sebagai dasar pola interaksi dalam bentuk sequence diagram.

\section{Identifikasi Sequence Diagram}

Identifikasi sequence diagram sesuai fitur yang ada di dalam sampel dilakukan dengan bantuan ModelGoonUML4Java plug-in pada IDE Eclipse.

\section{Menjabarkan Aktivitas Pada Setiap Fitur}

Penjabaran aktifitas pada setiap sequence diagram dibutuhkan untuk memetakan langkah kegiatan pada setiap fitur berdasarkan uji coba menjalankan aplikasi dan sequence diagram yang telah diidentifikasikan. Aktifitas ini nantinya digunakan sebagai dasar alur logika pembangunan pola interaksi dalam bentuk sequence diagram.

\section{E. Analisis Pola Interaksi}

Identifikasi pada pola interaksi sequence diagram dilakukan pada setiap fitur dan didasari oleh aktifitas yang sudah didapat sebelumnya. Analisis pola interaksi dilakukan untuk memetakan pola interaksi pada sequence diagram.

\section{F. Evaluasi Pola Interaksi Sequence Diagram}

Evaluasi pola dilakukan untuk menguji apakah pola interaksi pada fitur dari sampel perangkat lunakbisa diterapkan untuk merancang sebuah perangkat lunak, dengan mengambil pola interaksi yang sebelumnya dihasilkan. Hasil evaluasi berupa kesimpulan apakah pola interaksi tersebut dapat atau tidak dapat diterapkan untuk merancang perangkat lunak.

\section{PEMBAHASAN}

\section{A. Pengumpulan Data Aplikasi}

Di bawah ini adalah sampel yang terkumpul:

1. AddVoicemailActivity

2. GameActivity \& MainActivity (TicTacToe)

3. JetBoy

4. CubeWallpaperSettings

5. WalkieTalkieActivity 
6. BroadcastReceiverNewSms

7. ContactManager

Dalam paper ini hanya akan membahas dua aplikasi contoh android saja yaitu AddVoicemailActivity dan ContactManager, hal ini dilakukan untuk mempermudah penyampaian hasil eksplorasi pola interaksi sequence diagram serta mempermudah proses evaluasi.

\section{B. Identifikasi Fitur}

Identifikasi fitur dilakukan sesuai fitur-fitur yang tersaji. Fitur-fitur yang terkumpul dapat dilihat pada Tabel 1.

\section{Identifikasi Sequence Diagram}

Beberapa contoh hasil pembangkitan sequence diagram mengunakan ModelGoonUML4Java plug-in adalah sebagai berikut :

1) Contact Manager: Fitur dari aplikasi ini adalah membaca kontak telepon serta menambah kontak baru. Identifikasi sequence diagram pada gambar 1 adalah fitur pengambilan kontak dari dalam handphone.

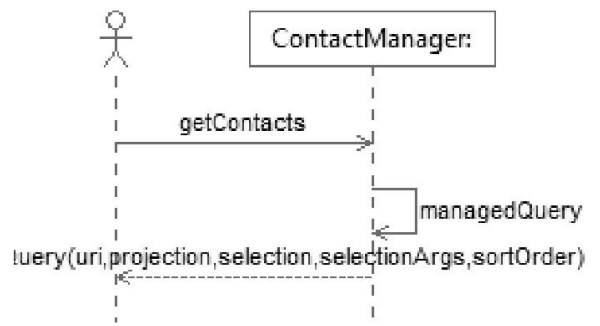

Gambar 1. Identifikasi sequence diagram untuk fitur pengambilan kontak dari handphone

2) Voicemail: Fitur dari aplikasi ini adalah merekam suara, menyimpan dan mengirim voicemail.Identifikasi sequence diagram pada gambar 2 berasal dari fitur storevoicemail.

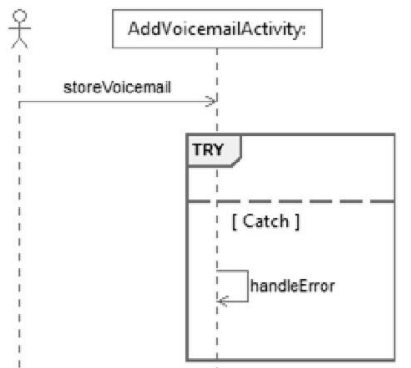

Gambar 2. Identifikasi sequence diagram untuk fitur store voicemail.

\section{Menjabarkan Aktifitas Fitur Yang \\ Terkumpul}

Berikut merupakan contoh pengambaran algoritma pada fitur-fitur yang ada dalam aplikasi android, yaitu pengambilan kontak dari telepon pada aplikasi contact manager, dan penyimpanan pesan suara pada aplikasi voicemail.

TABEL 1. HASIL IDENTIFIKASI FITUR

\begin{tabular}{|c|c|c|c|}
\hline No. & \begin{tabular}{|l|} 
Nama \\
Perangkat \\
Lunak \\
\end{tabular} & Keterangan & Fitur \\
\hline 1. & Voicemail & $\begin{array}{l}\text { Sampel ini } \\
\text { menunjukkan } \\
\text { bagaimana } \\
\text { merekam } \\
\text { suara, } \\
\text { menyimpan } \\
\text { dan mengirim } \\
\text { voicemail. }\end{array}$ & $\begin{array}{l}\text { i.Merekam suara } \\
\text { dengan } \\
\text { VoiceRecorder } \\
\text { ii. Handling hasil } \\
\text { rekaman suara } \\
\text { iii.Storevoicemail }\end{array}$ \\
\hline \multirow[t]{2}{*}{2.} & \multirow[t]{2}{*}{ TicTacToe } & $\begin{array}{l}\text { Sampel yang } \\
\text { tersedia ini } \\
\text { berisi mesin } \\
\text { utama game } \\
\text { ini, berjalan } \\
\text { ketika user } \\
\text { memilih } 2 \\
\text { pilihan dari } \\
\text { Playerfirstatau } \\
\text { computerfirst }\end{array}$ & \begin{tabular}{|rl} 
i. & Memproses masuk \\
& kepada game ketika \\
& user memilih \\
& Playerfirst atau \\
& computerfirst \\
ii. & SensoringInput \\
& ketika user \\
& memasukkan sesuai \\
& tile yang berlaku \\
& pada permainan. \\
iii. & Memproses input \\
& dari user dan \\
& menentukan \\
pemenang.
\end{tabular} \\
\hline & & $\begin{array}{l}\text { Sampel berisi } \\
\text { aktivitas } \\
\text { utama pada } \\
\text { game } \\
\text { TicTacToe, } \\
\text { muncul } \\
\text { pertama kali } \\
\text { ketika } \\
\text { program } \\
\text { dijalankan. } \\
\end{array}$ & $\begin{array}{ll}\text { i. } & \text { Startgame } \\
\text { memanggil } \\
\text { gameActivity }\end{array}$ \\
\hline 3. & JetBoy & Game & $\begin{array}{ll}\text { i. } & \text { Inisiasi program } \\
\text { dengan memanggil } \\
\text { dialog dan } \\
\text { permainan } \\
\text { ii. } & \text { Sensor Sentuhan } \\
\text { sesuai keypressup, } \\
\text { down maupun } \\
\text { onclick }\end{array}$ \\
\hline 4. & $\begin{array}{l}\text { Cube } \\
\text { Wallpaper }\end{array}$ & $\begin{array}{l}\text { DemoLiveWall } \\
\text { paper } \\
\text { sederhana }\end{array}$ & $\begin{aligned} & \text { i. } \text { Sensor Sentuhan } \\
& \text { ii. } \text { Generator grafis } \\
& \text { kubus/decahedron } \\
&\end{aligned}$ \\
\hline 5. & $\begin{array}{l}\text { Walkie } \\
\text { Talkie }\end{array}$ & $\begin{array}{l}\text { Demo } \\
\text { sederhana } \\
\text { VoIP } \\
\text { menggunakan } \\
\text { akun SIP dan } \\
\text { berkomunikasi } \\
\text { seperti } \\
\text { WalkieTalkie }\end{array}$ & $\begin{aligned} \text { i. } & \text { RegisterAccount } \\
& \text { lewat SIP (VoIP } \\
& \text { Provider) } \\
\text { ii. } & \text { Call dan Receivecall }\end{aligned}$ \\
\hline 6. & $\begin{array}{l}\text { Broadcast } \\
\text { Receiver } \\
\text { New SMS }\end{array}$ & $\begin{array}{l}\text { Aplikasi } \\
\text { sederhana } \\
\text { untuk } \\
\text { memberi } \\
\text { notifikasi } \\
\text { apabila ada } \\
\text { SMS akan } \\
\text { masuk }\end{array}$ & $\begin{aligned} & \text { i. } \text { Mengambil } \\
& \text { informasi tentang } \\
& \text { SMS yang akan } \\
& \text { masuk } \\
& \text { ii. } \\
& \text { Menampilkan isi } \\
& \text { SMS }\end{aligned}$ \\
\hline 7. & $\begin{array}{l}\text { Contact } \\
\text { Manager }\end{array}$ & $\begin{array}{l}\text { Demo } \\
\text { pengelola } \\
\text { kontak } \\
\text { sederhana di } \\
\text { telepon } \\
\text { genggam } \\
\end{array}$ & $\begin{aligned} & \text { i. } \text { Membaca kontak } \\
& \text { dari telepon dan } \\
& \text { menampilkannya } \\
& \text { sesuai abjad } \\
& \text { ii. } \\
& \text { Menambah kontak } \\
& \text { baru }\end{aligned}$ \\
\hline
\end{tabular}




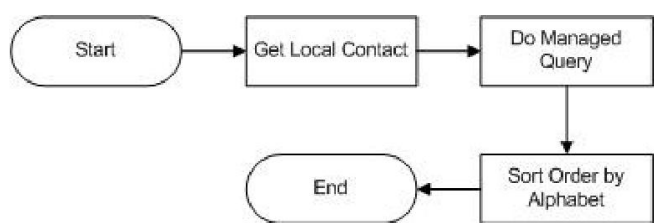

Gambar 3. Aktifitas pada pengambilan kontak di local storage handphone

1) Sampel Contact Manager: Pada gambar 3, ditunjukkkan algoritma pengambilan kontak dari local storage handphone. Aktifitas dalam algoritma tersebut adalah melakukan pengambilan kontak lokal dan kemudian menampilkannya sesuai dengan proyeksi urutan.

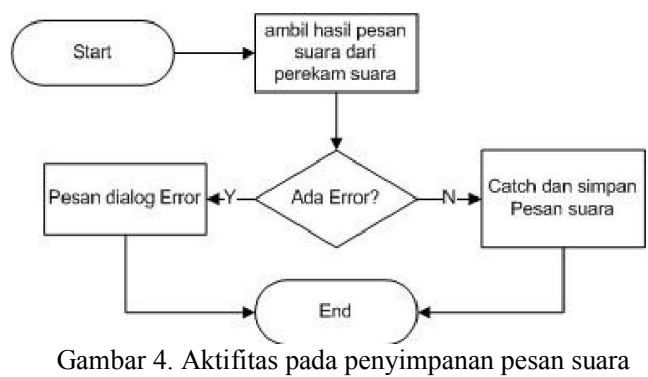

2) Sampel Voicemail: Pada gambar 4, ditunjukkan algoritma store voicemail. Aktifitas dalam fitur ini adalah menyimpan suara dari perekam suara dan kemudian memeriksa apakah ada kesalahan atau tidak, jika ada menampilkan dialog error.

\section{E. Analisa Pola Interaksi}

Aktifitas dan sequence diagram yang telah diidentifikasikan pada tahap sebelumnya digunakan untuk melakukan analisa untuk penentuan pola interaksi. Hal tersebut dilakukan dengan meneliti pola-pola yang muncul pada sequence diagram pada setiap objek-objek yang tersedia dan dikaitkan dengan aktivitas pada fitur tersebut. Aktifitas dan method difilter dan dicari yang merupakan method yang utama dalam mejalankan suatu fitur, method tersebut kemudian digambarkan ulang dalam bentuk sequence diagram dan menjadi pola interaksi sequence diagram untuk menjalankan suatu fitur.

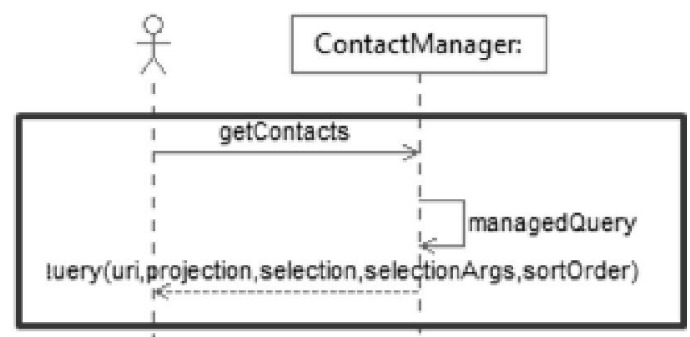

Gambar 5. Hasil identifikasi pola interaksi sequence diagram pengambilan kontak dari handphone

Contoh hasil identifikasi dan analisa pola interaksi sequence diagram ditampilkan pada gambar 5 dan gambar 6. Pada Tabel 2, ditampilkan hasil pola interaksi yang berupa katalog.Katalog pola interaksi sequence diagram yang ditampilkan dalam paper ini merupakan hasil analisa dari 2 aplikasi contoh android yaitu Voicemail\&Contact Manager.

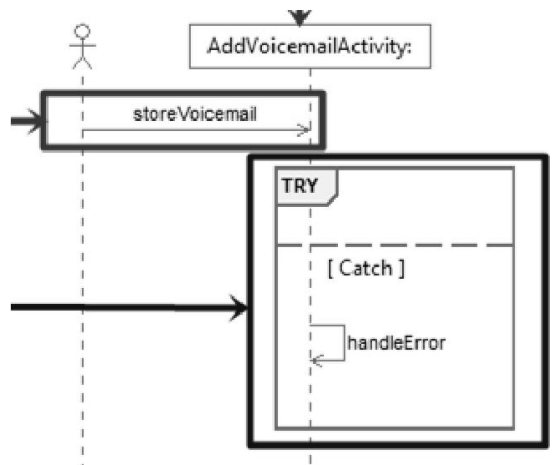

Gambar 6. Hasil identifikasi pola interaksi sequence diagram fitur store voicemail

\section{F. Evaluasi Pola Interaksi Sequence Diagram}

Evaluasi dilakukan dengan mengunakan pola interaksi sequence diagram yang diperoleh untuk diterapkan dalam studi kasus. Dalam evaluasi ini akan dibuat aplikasi yang memiliki kemampuan untuk mengirim pesan suara sesuai kontak yang dipilih.Aplikasi ini mengambil informasi kontak yang dipilih untuk dijadikan tujuan pengiriman pesan suara.

Aplikasi ini memanfaatkan pola interaksi sequence diagram yang telah diidentifikasikan pada Tabel 2 untuk melakukan desain aplikasi mengunakan model sequence diagram, desain sequence diagram untuk aplikasi ini bisa dilihat pada gambar 7. Fitur yang digunakan dari pola interaksi sequence diagram adalah Membaca kontak dari telepon dan merekam suara.

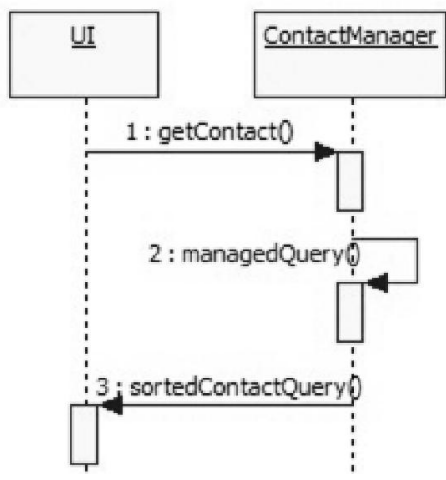

Gambar 7. Sequence Diagram untuk aplikasi mengirim pesan suara sesuai kontak yang dipilih

Aktivitas dari aplikasi ini adalah menampilkan kontak telepon, kemudian penguna bisa memilih salah satu kontak yang telah ditampilkan, dan bisa merekam voicemail. Pengguna kemudian bisa mengirim voicemail tersebut dengan tujuan kontak yang telah dipilih.Pada gambar 8 disajikan hasil run pada perangkat lunak untuk evaluasi. 
TABEL 2.KATALOG POLA INTERAKS

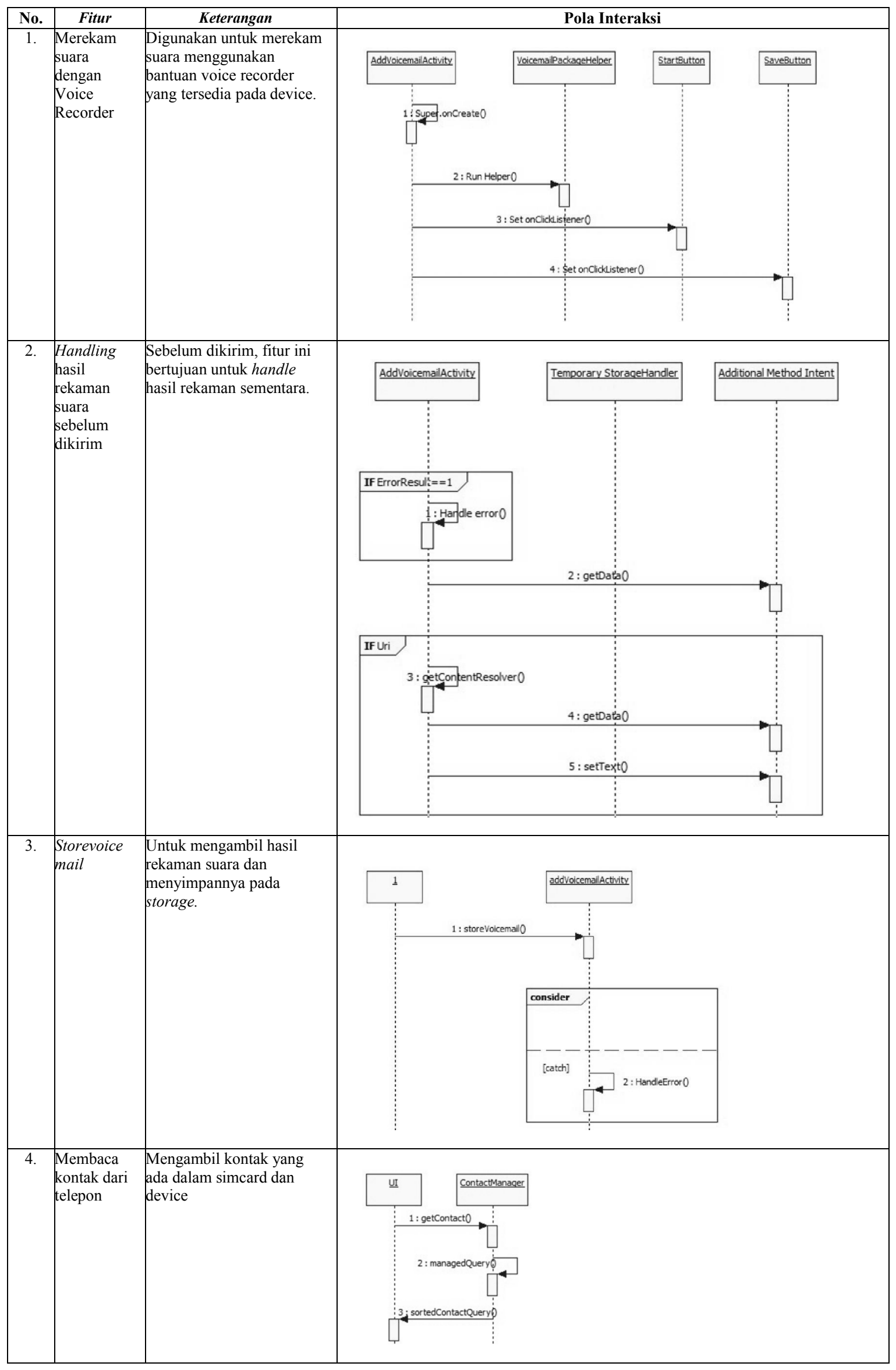


TABEL 2.KATAlog POLA INTERAKSI (LANJUTAN)

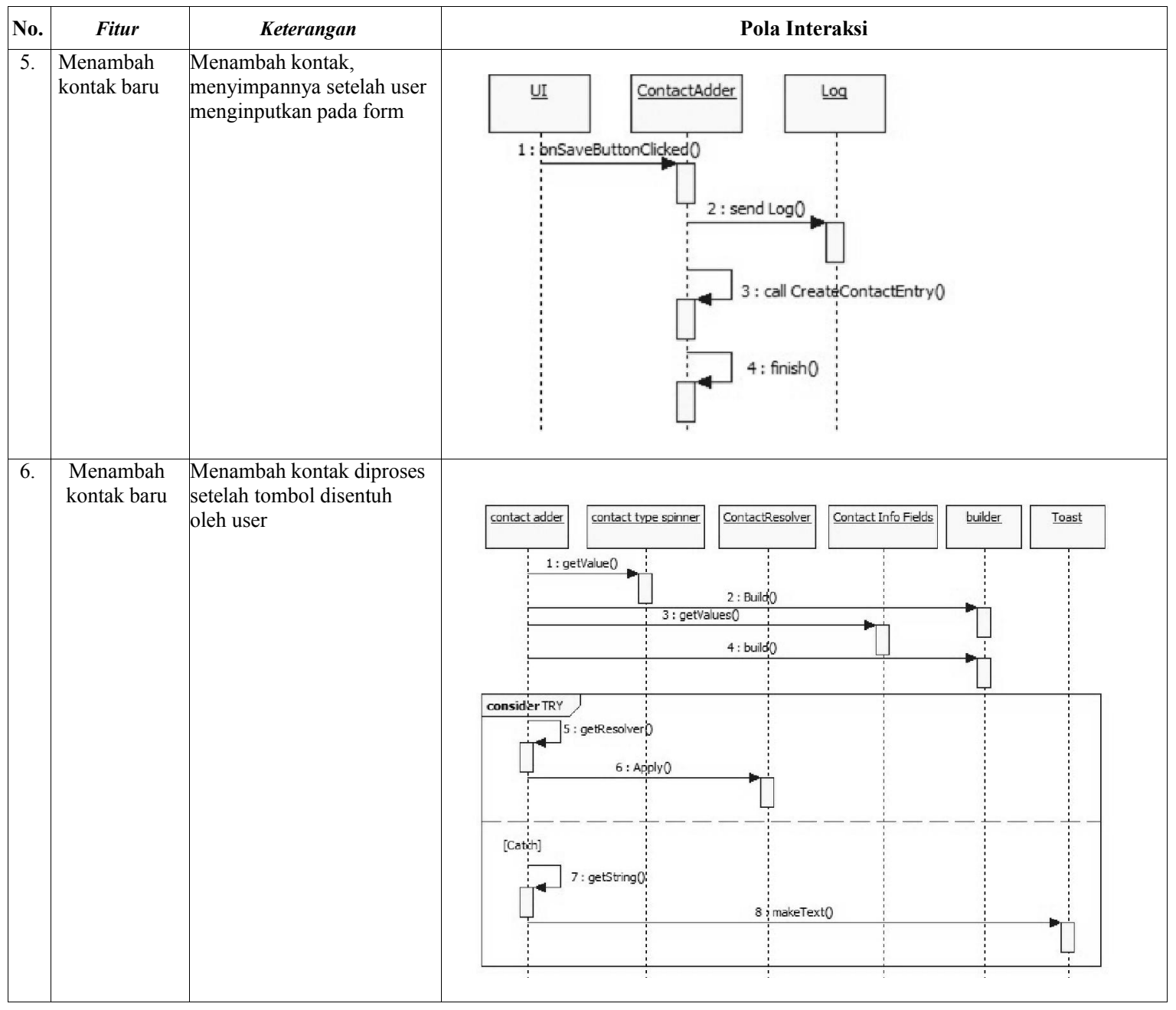

Dari hasil uji coba didapatkan bahwa pola interaksi sequence diagram yang telah dibuat bisa membantu dalam melakukan perancangan sequence diagram untuk aplikasi yang mengunakan fitur yang telah diidentifikasikan pada pola interaksi sequence diagram. Analis sistem bisa menggunakan template pola dalam merancang sequence diagram untuk kebutuhan perancangan sistem.

Solusi perancangan perangkat lunak dapat menggunakan pola interaksi yang telah didefinisikan, karena fitur yang dirancang memiliki kesamaan. Namun dengan penggunaan pola interaksi tersebut, dibutuhkan tambahan informasi source code perancangan aplikasi untuk setiap fiturnya. Beberapa method bisa mengunakan source code yang diambil dari aplikasi asal,terdapat kemungkinan dibutuhkan pula modifikasi pada source code tersebut. Namun fitur yang tidak tersedia pada pola interaksi sequence diagram, source code harus dilengkapi sendiri oleh programmer.

Keterbatasan dari pengunaan pola interaksi sequence diagram ini adalah pola fitur tersebut harus telah memiliki aplikasi yang telah berjalan dan telah diidentifikasikan polanya. Jika pola telah didefinisikan maka pola bisa diaplikasikan pada perancangan sequence diagram suatu aplikasi, namun jika belum maka analis sistem tetap harus melakukan perancangan sendiri sequence diagram aplikasi yang hendak dibuat.

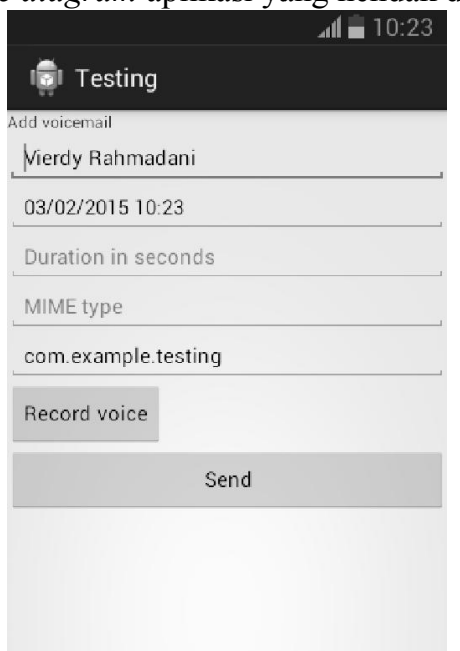

Gambar 8. Hasil run pada perangkat lunak untuk evaluasi

Penerapan Reverse Engineering Dalam Penentuan Pola Interaksi Sequence Diagram Pada Sampel 


\section{KESIMPULAN}

Pola interaksi sequence diagram yang diidentifikasikan dari tahapan penelitian ini, berdasarkan uji coba penerapan studi kasus dapat diterapkan sebagai template pola untuk mendesain sequence diagram. Sistem analis maupun programmer bisa mengunakan template pola ini untuk memudahkan perancangan sequence diagram. Karena pola ini merupakan hasil reverse engineering dari fitur suatu aplikasi yang telah berjalan maka penerapannya memastikan akan konsistensi desain dan implementasi, namun berdasarkan hasil evaluasi studi kasus tidak menutup kemungkinan dibutuhkan modifikasi source code untuk memastikan kesesuaian pola fitur dengan tujuan aplikasi yang mengunakan template pola interaksi sequence diagram tersebut.

Integrasi pembangkitan source code berdasarkan pola interaksi sequence diagram bisa dilakukan untuk penelitian selanjutnya, karena method yang teridentifikasi ini merupakan sourcecode dari aplikasi yang telah berjalan. Penerapannya bisa dimanfaatkan untuk pengembangan metode model-driven development.

\section{DAFTAR PUSTAKA}

Mens, T., Van Der Straeten, R., \& Simmonds, J. (2003). Maintaining Consistency between UML Models with Description Logic Tools. 6th International Conference on the Unified Modeling Language - the Language and its applications (UML'2003), (hal. 71-77). San Francisco.

Pressman, R. S. (2010). Software Engineering: A Practitioner's Approach, 7th Edition. New York: McGraw-Hill.

Shi, N., \& Ollson, R. A. (2006). Reverse Engineering of Design Patterns from Java Source Code. 21st IEEE/ACM International Conference on Automated Software Engineering (ASE 2006), $1-2$.

Stringfellow, C. (2006). Comparison of Software Architecture Reverse Engineering Methods. Dalam C. Stringfellow, Information and Software Technology 48.6 (hal. 484-497).

Tonella, P., \& Potrich, A. (2005). Monographs in Computer Science: Reverse Engineering of Object-oriented code. Boston: Springer Science.

Xiaoshan, L. (2006). A Characterization of UML Diagrams and Their Consistency. Engineering of Complex Computer System, 11th IEEE International Conference. 
[This Page Intentionally Left Blank] 